\title{
Orientation of the Atomic Groups of Poly( $\gamma$-benzyl glutamate)s in Liquid Crystalline States
}

\author{
Eisaku IIzUKA \\ Institute of High Polymer Research, Faculty of Textile Science and Technology, \\ Shinshu University, Ueda, Japan.
}

(Received June 17, 1975)

\begin{abstract}
The infrared dichroic ratio of liquid crystalline solutions of poly $(\gamma$-benzyl glutamate)s was measured in static electric fields; the transition moment directions of some of the absorption bands of the polypeptide molecules were calculated and compared with those reported for the solid film. In the poly( $\gamma$-benzyl-L-glutamate)-dibromomethane preparation, the orientations of both the main chain and the side chains, especially at low temperatures $\left(1^{\circ} \mathrm{C}\right)$ are very similar to those observed in the solid film; however, the rotation of the phenyl groups of the solid chain groups becomes noticeable beyond room temperature $\left(27,50^{\circ} \mathrm{C}\right)$. Among the preparations tested, no noticeable difference was detected by this method.
\end{abstract}

KEY WORDS Poly( $\gamma$-benzyl glutamate)s / Liquid Crystals / ElectricField Orientation / Transition Moment Direction / Phenyl Group / Infrared Dichroism / Atomic-Group Orientation /

From several pieces of experimental evidence, ${ }^{1-12}$ the author has proposed the idea that, in liquid crystalline solutions of polypeptides, rod-like molecular clusters are formed (or separated from domains) and oriented under the action of a static electric field, a static magnetic field, or shearing stresses. In PBLG (poly $(\gamma-$ benzyl-L-glutamate))-dibromomethane preparation, the molecular cluster is composed of some $5 \times 10^{5}$ polypeptide molecules of degree of polymerization 650 which present a parallel or nearly parallel ordering; the cluster has the size of "a few to several microns $\times 0.1 \mu \phi$ " and has a huge electric dipole moment due to fluctuations of the polymer aggregates (of the head-to-tail type) in both directions. The circular dichroism measurement of liquid crystalline solutions of PBLG has suggested that the side chains of the polypeptide molecule are both oriented and restricted from rotating and that the benzene rings in the side chains might associate with each other. These ideas have been reviewed elsewhere. ${ }^{13-15}$

The measurement of the infrared dichroic ratio provides information about the molecular conformation of polymer molecules and is very useful in studying their orientation as well. The directions of the atomic groups of $\alpha$-helical PBLG have been studied with respect to the fiber axis on mechanically oriented films by Tsuboi. ${ }^{16}$ In order to make the observed and calculated directions agree more closely for every transition moment, the modified $\alpha$-helix model has been proposed: in this the $\mathrm{C}=\mathrm{O}$ bond, the $\mathrm{C}-\mathrm{N}$ bond, and the peptide plane are, respectively, at $21^{\circ}\left(12^{\circ}\right), 80^{\circ}\left(71^{\circ}\right)$, and $10^{\circ}\left(7^{\circ}\right)$ with respect to the fiber axis. The values in the parentheses are for the $\alpha$-helix whose atomic coordinate is given by Trotter and Brown. ${ }^{17}$ The electricfield orientation of liquid crystalline solutions of $\mathrm{PBLG}^{1,2}$ and poly( $\gamma$-ethyl glutamate)s has been studied in a quartz cell at $3300 \mathrm{~cm}^{-1}$, which is the center of the $\mathrm{NH}$ stretching vibration mode of the polypeptide. The purpose of this paper is to present some results obtained by means of the infrared dichroic ratio concerning the molecular conformation of PBLG in liquid crystalline states (or I should say, in the "molecular cluster") as compared with that of PBLG in the solid state.

\section{EXPERIMENTAL}

The PBLG used was of mean degree of polymerization 1100 and was prepared by Professor 
T. Hayakawa of this Institute. The PBDG (poly( $\gamma$-benzyl-D-glutamate)) used was of mean degree of polymerization 1180 and was purchased from Pilot Chemicals, Inc. PBLG or an equimolar mixture of PBLG and PBDG was dissolved in a solvent such as dibromomethane, dichloromethane, or chloroform that allows the formation of $\alpha$-helices and was kept a few weeks in a sample tube at room temperature before using to allow the full growth of the liquid crystals. The solvents were of reagent grade and were used without further purification.

The solution was put in $\mathrm{a} \mathrm{CaF}_{2}$ cell of path length $2 \mathrm{~mm}$ which was kindly made by Japan Spectroscopic Co., Ltd., and a $\mathrm{CaF}_{2}$ spacer $8 \mathrm{~mm}$ wide was introduced in the cell to adjust the path length to 25 or 50 microns, with platinum needle electrodes attached to the both edges to apply a static electric field to the solution. Measurements of the dichroic ratios were then carried out with the incident beam perpendicular to the direction of the external field (169-338 $\mathrm{V} / \mathrm{cm}$ ) using a Jasco prism spectrometer DS-301 with a $\mathrm{AgCl}$ polarizer. The imperfection of this polarizer when placed in the spectrometer was 0.068 at $3300 \mathrm{~cm}^{-1}$ and 0.070 at $1000 \mathrm{~cm}^{-1}$. In carrying out the measurements, the external field direction (and the orientation direction of the solution) and the electric vector of the polarized beam were always placed at $45^{\circ}$ with respect to the entrance slit of the spectrometer to eliminate the error in the observed dichroic ratio due to polarization of the monochrometer, as found in the previous measurements. ${ }^{1,2}$

\section{RESULTS AND DISCUSSION}

The infrared absorption spectra of an electrically oriented liquid crystalline solution of PBLG are shown in Figure 1. Both the features of the spectra and the wave numbers of the transition moments are very close to those observed by Tsuboi $^{16}$ for the mechanically oriented film, except that the $\mathrm{NH}$ stretching vibration and the Amide I bands make a blue shift of about 10 $\mathrm{cm}^{-1}$ in solution as compared with those in the solid state. The infrared dichroic ratios were calculated for some of the absorption bands, as shown in this figure, from the observed values of the apparent transmission, using the equa-

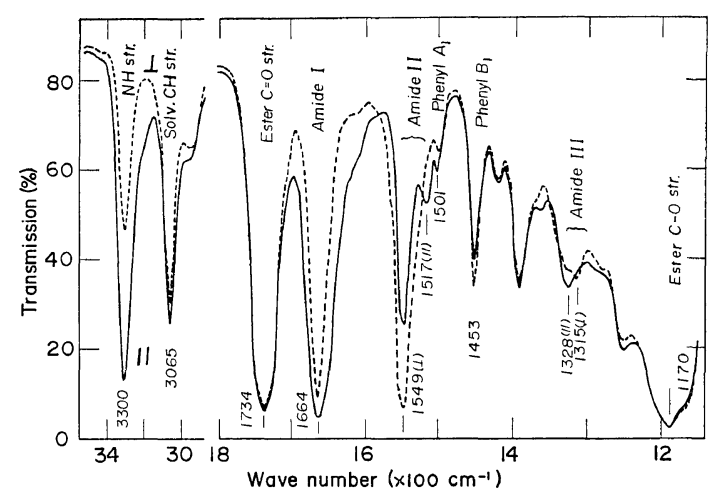

Figure 1. Infrared absorption spectra of an oriented dibromomethane solution of poly $(\gamma$-benzyl-L-glutamate). Oriented in an electric field $(281 \mathrm{~V} / \mathrm{cm})$; degree of polymerization, 1100 ; polymer concentration, 13.7 vol\%; and path length, $25 \mu$.

tions ${ }^{16,18}$ which were derived including the imperfection of the polarizer.

In a previous paper, ${ }^{2}$ a system of rods in which the rod axes were distributed in a static electric field according to the Boltzmann distribution law was treated. The absorbance of light polarized parallel to the external field $(E), D_{\|}$, and that for light perpendicular to $E, D_{\perp}$, were then obtained in terms of $E$, the dipole moment of the rod $(\mu)$, the Boltzmann constant $(k)$, absolute temperature $(T)$, and the tilt angle $(\gamma)$ that the direction of the transition moment in question makes with respect to the rod axis (and to the dipole of the rod). The orientation factor of the solution, $\Phi$, is given in the form:

$$
\Phi=\frac{1}{2}\left(3\left\langle\cos ^{2} \theta\right\rangle_{\mathrm{A} V}-1\right)=\frac{\left(D_{\|} / D_{\perp}\right)-1}{\left(D_{\|} / D_{\perp}\right)+2} \frac{2}{2-3 \sin ^{2} \gamma}
$$

where $\theta$ is the tilt angle that the rod axis makes with the external field direction. This equation was used to calculate the direction of each transition moment from the corresponding (corrected) dichroic ratio, $D_{\|} / D_{\perp}$, whereas Tsuboi used another equation ${ }^{19}$ derived for samples with a fully oriented portion plus a portion which is random in three dimensions. In molecular aggregates of the polypeptide, it is safe to assume that the polypeptide molecules present a parallel (or nearly parallel) ordering, ${ }^{20}$ and the direction of the polypeptide molecule can be assumed parallel to the rod axis (the molecular cluster 


\section{E. IIZUKA}

Table I. Transition moment directions of some of the absorption bands of poly( $\gamma$-benzyl glutamate)s

\begin{tabular}{|c|c|c|c|c|c|}
\hline \multirow{2}{*}{ Transition moment } & \multicolumn{3}{|c|}{ PBLG $/ \mathrm{CH}_{2} \mathrm{Br}_{2}$} & \multirow{2}{*}{$\frac{1: 1 \mathrm{PBLG}-\mathrm{PBDG} / \mathrm{CH}_{2} \mathrm{Br}_{2}}{27^{\circ} \mathrm{C}}$} & \multirow{2}{*}{$\begin{array}{l}\text { a } \mathrm{PBLG} \\
\text { film }\end{array}$} \\
\hline & $1^{\circ} \mathrm{C}$ & $27^{\circ} \mathrm{C}$ & $50^{\circ} \mathrm{C}$ & & \\
\hline $\mathrm{NH}$ str. & 29 & $29.4 \pm 1.17$ & 28 & 28 & 28 \\
\hline Ester $\mathrm{C}=\mathrm{O}$ str. & 53 & $53.4 \pm 0.52$ & 53 & 53 & 53 \\
\hline Amide I ( $\mathrm{C}=\mathrm{O}$ str. $)$ & 38 & $40.0 \pm 4.07$ & 40 & 39 & 39 \\
\hline Amide II (NH def.) & - & $81.7 \pm 4.94$ & 72 & - & 75 \\
\hline Phenyl $A_{1}$ (C-C str.) & 48 & $49.1 \pm 2.68$ & 49 & 50 & $\sim 46$ \\
\hline Phenyl $\mathrm{B}_{1}$ (C-C str.) & 61 & $59.0 \pm 1.02$ & 57 & 60 & 61 \\
\hline Amide III & 41 & $41.8 \pm 1.96$ & 42 & 43 & $\sim 40$ \\
\hline Ester $\mathrm{C}-\mathrm{O}$ str. & $\sim 54$ & $\sim 54$ & $\sim 54$ & $\sim 54$ & 54 \\
\hline Phenyl $\mathbf{B}_{2}$ & - & - & - & - & 62 \\
\hline
\end{tabular}

a From M. Tsuboi.16

Table II. Transition moment directions of some of the absorption bands of poly( $\gamma$-benzyl glutamate)s

\begin{tabular}{|c|c|c|c|c|c|}
\hline \multirow{2}{*}{ Transition moment } & \multicolumn{2}{|c|}{ PBLG } & \multicolumn{2}{|c|}{$1: 1$ PBLG-PBDG } & \multirow{2}{*}{ a PBLG film } \\
\hline & $\mathrm{CH}_{2} \mathrm{Cl}_{2}$ & $\overline{\mathrm{CHCl}_{3}}$ & $\mathrm{CH}_{2} \mathrm{Cl}_{2}$ & $\mathrm{CHCl}_{3}$ & \\
\hline NH str. & 30 & 29 & 29 & 30 & 28 \\
\hline Ester $\mathrm{C}=\mathrm{O}$ str. & 53 & 52 & 53 & 52 & 53 \\
\hline Amide I & 35 & 37 & 36 & 37 & 39 \\
\hline Amide II & 79 & 74 & 77 & 73 & 75 \\
\hline Phenyl $\mathbf{A}_{1}$ & 49 & 50 & 50 & 48 & $\sim 46$ \\
\hline Phenyl $\mathrm{B}_{1}$ & 59 & 61 & 59 & 61 & 61 \\
\hline Amide III & 40 & 39 & 37 & 41 & $\sim 40$ \\
\hline
\end{tabular}

a From M. Tsuboi. ${ }^{16}$

axis). According to the calculation by Miyazawa and Blout, ${ }^{21}$ the absorption peak in the perpendicular spectrum corresponding to that at 1515 $\mathrm{cm}^{-1}$ in the parallel spectrum should be at 1549 $\mathrm{cm}^{-1}$ and there should be no peak at $1549 \mathrm{~cm}^{-1}$ in the parallel spectrum. This means that the angle $\gamma$ for the $1515-\mathrm{cm}^{-1}$ absorption band is $0^{\circ}$, and the orientation factor is then calculated with the equation given in this text. In consequence, the angle $\gamma$ for each transition moment can be estimated from the corresponding $D_{\|} / D_{\perp}$ value. A certain portion of the polypeptide molecules (some $15 \%$ for PBLG-dibromomethane preparation) is considered not to be incorporated into liquid crystals; ${ }^{2}$ however, the difference between the values of $\gamma$ calculated with and without considering this was smaller than $1^{\circ}$.

In Tables I and II, the transition moment directions of some of the atomic groups of PBLG in the liquid crystalline state are summarized. Each value is the average of at least duplicate runs, except for the PBLG-dibromomethane preparation (at $27^{\circ} \mathrm{C}$ ) where thirteen runs were averaged. It may be seen in this preparation that the transition moment directions at $1^{\circ} \mathrm{C}$ coincide with those for the solid film within the limits of the experimental error. This indicates that the molecular conformation of the polypeptide molecule is very similar in both the molecular cluster and the solid film and is in accordance with the assumption that the polypeptide molecules present a parallel (or nearly parallel) ordering in the molecular cluster. It may also be seen that at higher temperatures $\left(27,50^{\circ} \mathrm{C}\right)$ the rotation of the phenyl groups becomes more striking than it is at $1^{\circ} \mathrm{C}$. Both viscoelastic and piezoelectric measurements of oriented films of PBLG show a dispersion at about $20^{\circ} \mathrm{C}$ when performed, respectively, at 20 and $30 \mathrm{~Hz}$; this is ascribed to the onset of thermal motions of the side chains of the $\alpha$-helical molecules in the noncrystalline regions. ${ }^{22}$ This disper- 

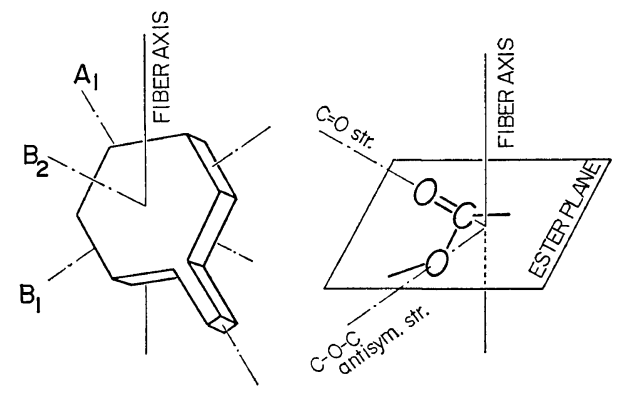

Figure 2. The ester and phenyl groups and their transition moments. [M. Tsuboi. ${ }^{16}$ Courtesy of John Wiley \& Sons, Inc.]

sion may be related to this infrared observation. The peptide and phenyl groups of the polypeptide molecule and their transition moments are illustrated in Figure 2, after the paper by Tsuboi ${ }^{16}$, in order to help get a rough idea about the orientation of these groups with respect to the fiber (or molecular) axis. The reader is encouraged to apply the angles given in Table I to the illustrations.

The $\alpha$-helix in the solid state is distorted in some cases: e.g., a PBLG film cast from a chloroform solution ${ }^{23}$ and a racemic film of PBLG and PBDG cast from a dioxane solution; ${ }^{24}$ however, no noticeable difference could be detected with this method among the various preparations tested (see Tables I and II). Liquid crystalline solutions of polypeptides undergo magnetic-field orientation and in turn the solvent molecules orient owing to electric dipole-dipole attractions in the molecular fields caused by the oriented polymer molecules $^{25}$ (the author should say "oriented molecular clusters"'). This is the case also in the electric-field orientation of liquid crystals of polypeptides. ${ }^{5,6}$ The orientation of the solvent molecules is ascertained by the dichroism of the solvent $\mathrm{C}-\mathrm{H}$ stretching vibration mode at about $3065 \mathrm{~cm}^{-1}$ for dibromomethane (see Figure 1).

\section{CONCLUSIONS}

In conclusion, the experimental evidence obtained in this study appears to support the following hypotheses concerning the molecular conformation of poly ( $\gamma$-benzyl glutamate)s in liquid crystalline states:

1. At a low temperature, say at $1^{\circ} \mathrm{C}$, the orientation of the atomic groups of poly $(\gamma$-benzyl-L-glutamate) in the molecular cluster is similar to that in the solid film.

2. The rotation of the phenyl groups in the side chains of poly $(\gamma$-benzyl-L-glutamate) becomes more striking in the molecular cluster at temperatures beyond room temperature.

3. No noticeable difference is detected among the various preparations: e.g., the L-isomer in dibromomethane, dichloromethane, or chloroform, and an equimolar mixture of the L- and the $\mathrm{D}$-isomers in these solvents.

Acknowledgments. The author wishes to thank Professor T. Hayakawa of this Institute for the donation of the polypeptide specimens used. His thanks are also due to Japan Spectroscopic Co., Ltd. for manufacturing the $\mathrm{CaF}_{2}$ cell used and Professor M. Tsuboi of The Uuiversity of Tokyo for allowing him to cite the figures from his paper.

\section{REFERENCES}

1. E. Iizuka, Biochim. Biophys. Acta, 175, 457 (1969).

2. E. Iizuka, ibid., 243, 1 (1971).

3. E. Iizuka and Y. Go, J. Phys. Soc. Japan, 31, 1205 (1971).

4. E. Iizuka, Polymer J., 4, 401 (1973).

5. E. Iizuka, ibid., 5, 62 (1973).

6. E. Iizuka, J. Phys. Soc. Japan, 34, 1054 (1973).

7. E. Iizuka, ibid., 35, 1792 (1973).

8. E. Iizuka, T. Keira, and A. Wada, Mol. Cryst. and Liq. Cryst., 23, 13 (1973).

9. E. Iizuka, ibid., 25, 287 (1974).

10. E. Iizuka, ibid., 27, 161 (1974).

11. E. Iizuka and J. T. Yang, ibid., 29, 27 (1974).

12. E. Iizuka, unpublished data.

13. E. Iizuka, Kobunshi (High Polymers, Japan), 21, 463 (1972).

14. E. Iizuka, Seibutsu Butsuri Biophysics Japan, 15, 133 (1975).

15. E. Iizuka, Adv. Polym. Sci., Springer-Verlag, Heidelberg, in press.

16. M. Tsuboi, J. Polym. Sci., 59, 139 (1962).

17. G. Herzberg, "Molecular Spectra and Molecular Structure," Vol. 2, Van Nostrand, New York, N.Y., 1951, p 365.

18. E. Charney, J. Opt. Soc. Amer., 45, 980 (1955).

19. M. Beer, Proc. Roy. Soc., A236, 136 (1956).

20. H. Mark and A. V. Tobolsky, "Physical Chemistry of High Polymeric Systems," 2nd ed, 
E. IIZUKA

Willey-Interscience, New York, N.Y., 1950, p 23. E. T. Samulski and A. V. Tobolsky, Biopoly229. mers, 10, 1013 (1971).

21. T. Miyazawa and E. R. Blout, J. Amer. Chem. 24. Y. Mitsui, Y. Iitaka, and M. Tsuboi, J. Mol. Soc., 83, 712 (1961). Biol., 24, 15 (1967).

22. T. Konaga and E. Fukada, J. Polym. Sci., 25. S. Sobajima, J. Phys. Soc. Japan, 23, 1070 (1967). Part A-2, 9, 2023 (1971). 